\title{
Organizational Ambidexterity, Exploration, Exploitation and Firms Innovation Performance
}

\author{
Mladenka Popadić1, Matej Černe ${ }^{2}$, Ines Milohnić1
}

\author{
${ }^{1}$ University of Rijeka, Faculty of Tourism and Hospitality Management Opatija, Croatia, \\ mpopadic@fthm.hr, ines.milohnic@fthm.hr \\ 2 University of Ljubljana, Faculty of Economics, Slovenia, \\ matej.cerne@ef.uni-lj.si
}

\begin{abstract}
Background and Purpose: The construct of organizational ambidexterity (OA) has attracted the growing attention in management research. Previous empirical research has investigated the effect of organisational ambidexterity on performance from various perspectives. This study aims to resolve the contradictory previous research findings on the relationship between organisational ambidexterity and innovation performance. We unpack this construct with combined dimension of ambidexterity, which relates to a combination of high levels of both exploration and exploitation (introduction of products or services that were new to the market and new to the firm).

Methodology: We frame our ambidexterity hypothesis in terms of firm's innovation orientation. The hypothesis is tested by using Community Innovation Survey (CIS) 2006 micro data at the organizational level in twelve countries. To operationalize an ambidexterity and firms innovation outcome, we used self-reported measures of innovativeness. Results: To test our hypothesis, we developed a set of models and tested them with multiple hierarchical linear regression analyses. The results indicate that exploration and exploitation are positively related to firm's innovation performances which supports our assumption that both are complementary. Furthermore, we find that above and over their independent effects, through combining them into a single construct of organizational ambidexterity, this variable remains negatively and significantly related to innovation performance.

Conclusion: These results provides the managers with an idea of when managing trade-offs between exploration and exploitation would be more favorable versus detrimental. For firms with lower organizational ambidexterity, the relationship between exploration-exploitation and the firm's innovation performance is a more positive one.
\end{abstract}

Keywords: organizational ambidexterity, exploration, exploitation, innovation performance

\section{Introduction}

A major challenge for firms is to simultaneously pursue both explorative (radical) and exploitative (incremental) innovation and thereby remain competitive on a long-run (March, 1991). The general agreement in the literature is that ambidextrous firms are those who are capable of both exploiting existing competencies and in the same time exploring new opportunities. Scholars in general agree with this original premise, but that is where the consensus in ambidexterity research comes to a halt. Moreover, beyond these points of agreements, there is considerable ambiguity and some vagueness regarding the nature of exploration and exploitation, and conversely ambidexterity construct (Cao, Gedajlovic, and Zhang, 2009; Junni, Sarala, Taras, and Tarba, 2013; O’Reilly and Tushman, 2013).

The main argument in OA research is that firms whether through combined or balanced OA are more like-

Received: March 26, 2015; revised: April 21, 2015; accepted; April 27, 2015

This article is the revised text of the paper presented at 34th International Conference on Organizational Science Development "Internationalization and Cooperation" (http://fov.uni-mb.si/conference/), which was held 25th-27th March 2015 in Portorož, Slovenia. 
ly to achieve better performance effects compared to ones who emphasize one activity over one (Junni et al., 2013; Raisch and Birkinshaw, 2008). However, the empirical the empirical evidence on the effects of OA on performance is still mixed (Junni et al., 2013). While one group of scholars have found a positive relationship (Gibson and Birkinshaw, 2004; He and Wong, 2004; Lubatkin, Simsek, Ling, and Veiga, 2006), others have a found a negative relationship (Atuahene-Gima, 2005; Atuahene-Gima and Murray, 2007), or no relationship at all (Venkatraman, Lee, and Iyer, 2007).

Both exploration and exploitation have been shown to positively affect organisational performance (Hernández-Espallardo, Sánchez-Pérez, and Segovia-López, 2011). Thus, a firm that engages in both exploration and exploitation is expected to maintain innovation, achieving reliability while enabling organizational renewal and thus enjoying enhanced performance (Stettner and Lavie, 2013). Some scholars have argued that exploration and exploitation are mutually exclusive, indication that relationship between exploration and exploitation is negative. In the other hand, Gupta, Smith, and Shalley (2006) argued that this not is necessary true and that relationship between exploration and exploitation may be positive.

In this paper, we embrace this suggestion and argued that both exploration and exploitation are associated with some amount of learning and innovation, albeit of different types (Baum, Calabrese, and Silverman, 2000; Benner and Tushman, 2002; Gupta et al., 2006; He and Wong, 2004). While being distinct sets of activities that rely on specific knowledge and capabilities (Kammerlander, Burger, Fust, and Fueglistaller, 2014; March, 1991; Raisch, Birkinshaw, Probst, and Tushman, 2009), complementary perspective seems appropriate. More specifically, we aim to examine the following research questions: What is the effect of a firm's exploration and exploitation activities on the firm's innovation performance, and what is the effect of organizational ambidexterity on this relationship?

Our study contributes to the literature in several ways. First and foremost, we advance research on organizational ambidexterity (Raisch and Birkinshaw, 2008), which focuses on the performances implications of a firms engagement in both exploration and exploitation. As such, our findings complement to greater clarity to the treatment of ambidexterity. Further, by studying how the effect of these distinct processes as mutually supportive enhances firm's innovation performance. Our empirical results partly support these expectations. Data from the Community Innovation Survey (CIS 2006) show that correlation between exploration and exploitation is positive and significant, which supports our assumption that exploration and exploitation are complementary variables, rather that two ends of a continuum. This paper proceeds as follows. In what follows, we develop theory with respect to the relationship between exploration, exploitation, organizational ambidexterity and innovation performance followed by the methodology section, which explains the empirical approach. The research results are reported followed by a discussion of the implications of our study for theory and practice and suggested directions for future research.

\section{Theory and hypotheses}

\subsection{The concept of organizational ambi- dexterity}

A growing number of studies argue that organizational ambidexterity is increasingly important for the sustained competitive advantage of firms (Junni et al., 2013). The original meaning of ambidexterity, i.e. an individual's capacity to be equally skilful with both hands, has become surprising well adapted to organization setting, broadly defined as an organization's capacity to do two different things equally well (Birkinshaw and Gupta, 2013), or to pursue both explorative and exploitative innovation $(\mathrm{O}$ Reilly and Tushman, 2004). This construct is now generally used in a wide variety of methodological setting, but March (1991) introduces concepts of exploration and exploitation to the management literature.

In March s characterization exploitation is related to "refinement, choice, production, efficiency, selection, implementation and execution" opposing it to exploration, which involves "search, variation, risk-taking, experimentation, play, flexibility, discovery, and innovation" (p. 71). Many scholars have started using ambidexterity as an integral construct to hallmark a firm's dual orientation with respect to the exploration and exploitation (Cao et al., 2009; Gibson and Birkinshaw, 2004; Tushman and O'Reilly, 1996). For instance, Lubatkin et al. (2006) define an ambidextrous organization as capable of exploiting existing competencies as well as exploring new opportunities. March (1991) conceptualize exploration and exploitation as two ends of continuum and therefore claimed that both must be fundamentally incompatible and will generally be mutually exclusive. One of the reasons of tensions between two activities is that both compete for scarce organizational resources (Gupta et al., 2006). If firm decides to invest more resources in exploitation logic dictates that fewer resources are left for exploration. Even though March conceptualization is indisputable, several scholars extended argument by threating exploration and exploitation as simultaneously achievable and thus orthogonal (Koza and Lewin, 1998; Rothaermel, 2001; Rothaermel and Alexandre, 2009).

This leads to the most notable differences in the conceptualization of OA construct. Concerning the March balance perspective, an OA can is an optimal point, on a continuum with exploration lying at one end and exploration 
on the other (Cao et al., 2009; March, 1991). Alternatively, proponents of orthogonal view, claim that they should be viewed as two separate and independent dimensions of firm activities (Gibson and Birkinshaw, 2004), implying that the combination of high levels of both exploration and exploitation should be achieved to maximize OA (Cao et al., 2009; Simsek, 2009). In this view, ambidexterity has been described as the capacity of the firm to purses high levels of both exploration and exploitation (Jansen, Simsek, and Cao, 2012; Lavie and Rosenkopf, 2006) rather that managing trade-offs to achieve an optimal balance between exploration and exploitation.

As firms are competing for limited resources they are faced with a trade-off situation, either "success trap" or a "failure trap" (March, 1991), a situation where a firm decides to invest heavily in exploitation, has fewer resources available for exploration and vice versa (Stadler, Rajwani, and Karaba, 2014). This one-path solution can be especially harmful for firms, especially for resource-constrained firms. In intra and inter-organizational contexts, scholars disagree concerning whether a particular difference in operationalization of balance between exploration and exploitation should be characterized as a binary, difference of kind or as a continuum - a difference of degree.

Although the transition from exploration to exploitation is gradual, the difference between these activities is often a matter of degree (Stettner and Lavie, 2013). This transitivity leads to the conceptualization of exploration and exploitation along a continuum (Lavie, Stettner, and Tushman, 2010). As distinction of exploration and exploitation call for conceptualization as continuum involving shades of explore-exploit, but often much hinges on which level (i.e., individual, intraorganizational, or interorganizational) these concern is exerted. Gupta et al. (2006) recommend approaching carefully in testing performance implications of pursuing exploration and exploitation activities, because the measurement of OA greatly vary across studies (Junni et al., 2013).

We embrace these upfront conflicting recommendations. The pursuit of exploration and exploitation is an inherently difficult task due to their opposite nature, because what drives the former is different from that which drives the latter (O'Reilly and Tushman, 2008; Raisch et al., 2009). Although March (1991) presumes that a continuum balanced approach of both exploration and exploitation is essential for performance, the literature is still inconclusive with regard to the specific effects of these different activities on firms innovation performance.

In our paper, we follow extant research (Gibson and Birkinshaw, 2004; Lavie et al., 2010) in assuming that both activities, while being distinct sets of activities that rely on specific knowledge and capabilities (Koza and Lewin, 1998; O'Reilly and Tushman, 2008; Raisch and Birkinshaw, 2008) are complementary activities (Kammerlander et al., 2014). The complementary perspective claims that exploration and exploitation are independent dimensions, but positively correlated and the underlying rationale behind this perspective is that firms benefit from previous investments in exploration process when making subsequent investments in the exploration ones. In sum, exploration and exploitation are complementary activities, as resources released through successful exploitation activities can furnish future exploratory activities (Bierly and Daly, 2007) Thus, there may be a synergistic effect between the two as well, and hence there is a need for firms to manage the balance between the two (He and Wong, 2004). Also in support of this view, Blindenbach-Driessen and Ende (2014) found support for orthogonal treatment of exploration and exploitation. Moreover they argued that exploratory innovation will lead to ideas for exploitation and thus facilitate a culture for innovation, which is also beneficial for exploitative innovation. Therefore, we hypothesize:

H1: Exploration is positively related to firm's innovation performance.

$\mathrm{H} 2$ : Exploitation is positively related to firm's innovation performance.

\subsection{Ambidexterity dimensions (explora- tion and exploitation) and innovation per- formance}

Benner and Tushman (2002) argued that exploitative innovations involve improvements in existing components and build on the existing technological trajectory, whereas exploratory innovation involves a shift to a different technological trajectory. In in the same line, He and Wong (2004) defined exploitative innovation as technological innovation activities aimed at improving existing product-market domains and exploratory innovation as technological innovation aimed at entering new product-market domains. The combined OA perspective proposes that high levels of both exploration and exploitation will enhance performance. With maintaining efficiency high in current operation, simultaneously new opportunities can be identified and captured in high level (Junni et al., 2013).

In such situations, firms can prevent organizational inertia (Simsek, 2009). As a consequence, combined ambidexterity involves a firm's effort to increase the combined magnitude of both exploratory and exploitative activities (Cao et al., 2009). One group of scholars stipulated that exploration and exploitation are fundamentally different logics that create tensions (Lavie et al., 2010; March, 1991) and that balance occurs when we match the magnitude of two types of activities (Lavie et al., 2010)(Lavie).

For instance, He and Wong (2004) argued the relative imbalance (measured as absolute difference) between exploration and exploitation is negatively related to sales 
growth rate, while the interaction between exploration and exploitation is positively related to sales growth rate. Gupta et al. (2006) point out an idea that both activities are not necessary in conflict. Exploration and exploitation can enhance each other because they can take place in complementary domains, which do not necessary, compete for the same resources (Gupta et al., 2006). Moreover, due to their basic incompatible nature (March, 1991) they require substantially different processes, structures, cultures and capabilities, and conversely affect performance differently (He and Wong, 2004; O'Reilly and Tushman, 2008; Raisch and Birkinshaw, 2008).

H3: Ambidexterity is positively related to firm's innovation performance.

\section{Methods}

\subsection{Measures}

We used CIS 2006 micro data (company level) for the main explanatory variables and control measures. The Community Innovation surveys (CIS) from different countries were used (i.e. Bulgaria, Cyprus, Czech Republic, Estonia, Norway, Portugal, Romania, United Kingdom, Slovakia, Slovenia, Spain and Switzerland).

Exploration and Exploitation. To operationalize exploration and exploitation we used questions from the Community Innovation Survey (CIS). Organizational ambidexterity is an integrative construct of exploration and exploitation, and therefore measure of ambidexterity is based on measures, exploration and exploitation. We followed the approach used by most ambidexterity studies (Cao et al., 2009; He and Wong, 2004; Lubatkin et al., 2006; Tushman and O'Reilly, 1996). The exploration and exploitation variables were framed in terms of firms innovation orientation, that is, its orientation towards introduction of new products or services that were technologically new to market (i.e. exploration) and/or the instruction of products or services that were technologically improved versions of existing ones e.g. new to the firm (i.e. exploitation).

Ambidexterity. We measured organizational ambidexterity - using exploration and exploitation variables. To operationalize ambidexterity we multiply exploration and exploitation. To mitigate the potential for multicollinearity we mean centred the exploration and exploitation variables before obtaining their product. This measurement is in line with generally accepted measures in ambidexterity literature. This measure is adapted from He and Wong (2004), Gibson and Birkinshaw (2004) and Cao et al. (2009) who used it in similar operational approach.

Firms Innovation Performance. To operationalize firm innovation performance, we follow the approach of previous studies that have conceptualized this variable using CIS data (Blindenbach-Driessen and Ende, 2014; Laursen and Salter, 2006; Oerlemans, Knoben, and Pretorius, 2013). Innovation performance is operationalized with one combined measure through which firm were asked to indicate the percentage of turnover introduced during 2004 to 2006 that is attributable to (1) products and services that are totally new-to-the-firm and (2) products and services that are new new-to-the-market. Originally, CIS question combines two latter categories and one more - products that stayed the same or had only minor modifications over the period 2004-2006. We believe that latter two categories capture essence of innovative performance, so we excluded this category from research. Furthermore, definitions of exploration and exploitation were included just before this CIS question to make sure that respondents interpret these categories in the same way and to improve construct validity (de Leeuw, Lokshin, and Duysters, 2013).

We included several control variables in the analysis. Firm size was used as a control variable. We follow prior study and calculated it as the logarithm of the number of employees in 2006. In line with Černe, Jaklič, and Škerlavaj (2013), geographic scope is operationalized as local (0), regional (1), national (2), or international (3). The variable $R \& D$ intensity is calculated by dividing the R\&D expenditures by the turnover (Blindenbach-Driessen and Ende, 2014).

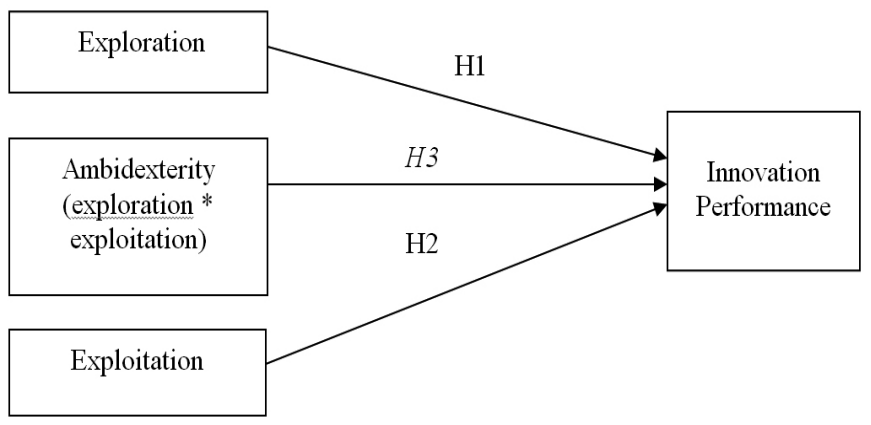

Figure 1: Research model with hypotheses 


\section{Results}

\subsection{Hierarchical regression analysis re- sults}

Descriptive statistics and correlations for all variables are provided in Table 1. The correlation between exploration and exploitation is positive and significant $(.19 ; \mathrm{p}<.01)$, which is in line with prior studies (Kammerlander et al., 2014), which provides our strong preliminary indication that exploration and exploitation are complementary rather that two end of a continuum. All individual variance inflation factors (VIF) were below 2 and thus below the critical value of 10 .

To test our hypothesis, we developed a set of models and tested them with multiple hierarchical linear regres- sion analyses. Model 1 in Table 2 reports the main effects of the control variables on innovation performance. Model 2 adds the main effects of exploratory and exploitative activities, which contribute $32 \%$ over the variance explained by the control variables. Model 3 adds their interaction term. First, we added exploration as a first predictor of innovation performance. The results show that exploitation is significantly and positively (thus, supporting Hypothesis 1) related to innovation performance (model $2: \mathrm{b}=.20$, s.e. $=.00, \mathrm{p}<.01)$. Exploitation, second predictor in the model 2 was positively and significantly related to innovation performance (model $2: \mathrm{b}=.32$, s.e. $=.00, \mathrm{p}<.01$ ). Therefore, Hypothesis 2 is also supported. Model 3 shows that the interaction effect between the two innovation activities on firms innovation performance is negative, but significant $(\mathrm{b}=-.32$, s.e. $=.01, \mathrm{p}<.01)$. Thus, Hypothesis 3 is not supported.

Table 1: Means, Standard Deviations, and Correlations ${ }^{a}$

\begin{tabular}{|c|c|c|c|c|c|c|c|c|c|}
\hline & Variable & Mean & SD & 1 & 2 & 3 & 4 & 5 & 6 \\
\hline 1 & Innovation performance & 0.21 & 0.33 & & & & & & \\
\hline 2 & Geographic scope & 0.26 & 0.44 & $0.08^{* *}$ & & & & & \\
\hline 3 & Firm size (log) & 0.62 & 0.71 & 0.00 & $0.33^{* *}$ & & & & \\
\hline 4 & R\&D intensity & 0.17 & 11.71 & $0.02^{* *}$ & 0.01 & 0.00 & & & \\
\hline 5 & Exploration & 0.27 & 0.45 & $0.34^{* *}$ & $0.17 * *$ & $0.11^{* *}$ & 0.00 & & \\
\hline 6 & Exploitation & 0.42 & 0.49 & $0.51^{* *}$ & $0.16^{* *}$ & $0.09^{* *}$ & $0.01^{*}$ & $0.19^{* *}$ & \\
\hline 7 & Ambidexterity & 0.04 & 0.22 & -0.11 & $0.02^{* *}$ & $0.05^{* *}$ & $-0.01^{*}$ & $0.21^{* *}$ & $0.09 * *$ \\
\hline
\end{tabular}

${ }^{a} n=33590 . * * p<.01, * p<.05$

Table 2: Hierarchical regression analyses for innovation performance as the dependent variable ${ }^{a}$

\begin{tabular}{|c|c|c|c|c|c|c|c|c|c|c|c|c|c|}
\hline \multirow{3}{*}{ Variables } & \multicolumn{13}{|c|}{ Innovation performance } \\
\hline & \multicolumn{5}{|c|}{ Model 1} & \multicolumn{4}{|c|}{ Model 2} & \multicolumn{4}{|c|}{ Model 3} \\
\hline & $b$ & $S E$ & $\beta$ & $t$ & & $b$ & $S E$ & $\beta$ & $t$ & $b$ & $S E$ & $\beta$ & $t$ \\
\hline Geographic scope & $0.07 * *$ & 0.00 & 0.09 & 15.84 & $-0.02 * *$ & 0.00 & -0.02 & -3.91 & -0.02 & $-0.02 * *$ & 0.00 & -0.03 & -5.90 \\
\hline Firm size $(\log )$ & $\mathrm{t}$ & 0.00 & -0.03 & -5.59 & $-0.03 * *$ & 0.00 & -0.07 & -14.21 & -0.03 & $-0.03 * *$ & 0.00 & -0.06 & -12.96 \\
\hline $\mathrm{R} \& \mathrm{D}$ intensity & $0.00 * *$ & 0.00 & 0.02 & 3.85 & $0.00 * *$ & 0.00 & 0.02 & 3.64 & 0.00 & $0.00^{*}$ & 0.00 & 0.01 & 3.30 \\
\hline Exploration & & & & & $0.20 * *$ & 0.00 & 0.26 & 56.72 & 0.20 & $0.23 * *$ & 0.00 & 0.31 & 67.05 \\
\hline Exploitation & & & & & $0.32 * *$ & 0.00 & 0.47 & 101.27 & 0.32 & $0.33 * *$ & 0.00 & 0.48 & 107.04 \\
\hline Ambidexterity & & & & & & & & & & $-0.32 * *$ & 0.01 & -0.21 & -47.80 \\
\hline $\mathrm{R}^{2}$ & \multicolumn{3}{|c|}{.01} & & & \multicolumn{3}{|c|}{.33} & & \multicolumn{4}{|c|}{.37} \\
\hline$F(d f)$ & \multicolumn{3}{|c|}{$89.05(33586,3)$} & & & \multicolumn{3}{|c|}{$3236.72(33584,5)$} & & \multicolumn{4}{|c|}{$3261.48(33583.00)}$, \\
\hline$\Delta \mathrm{R}^{2}$ & \multicolumn{3}{|c|}{.01} & & & \multicolumn{3}{|c|}{.32} & & \multicolumn{4}{|c|}{.04} \\
\hline
\end{tabular}

$* * p<.01, * p<.05$ 


\section{General discussion and conclusion}

While the effects of organization ambidexterity on performance have been focus of a variety industry and methodological setting, the empirical results have been mixed. Our study aimed to enhance our understanding how exploration and exploitation activities affect the firm's innovation performance. Specifically, we adopt a combined perspective, and study ambidexterity as the combined magnitude of exploration and exploitation, which correspond to the notion that exploration and exploitation are orthogonal activities, bur complementary (Cao et al., 2009). In such orthogonal relation, two types of activities can stimulate each other (Blindenbach-Driessen and Ende, 2014).

The empirical results revealed strong positive effects of exploration and activities on the firm's innovation performance. These findings extend previous ambidexterity studies and found a positive correlation between exploration and exploitation, which supports the view that exploration and exploitation have an orthogonal relationship and thus complements each other.

Empirically, unpacking the ambidexterity construct into exploration and exploitation variables has proven to be beneficial as each variable only through their main effect and not interaction with other, has explained innovation performance. In particular, it appears that diminishing returns occur when both processes are combined, as is indicated by the negative interactive effect of exploitative and exploratory activities on firm's innovation performance. This coincides with Atuahene-Gima (2005) research who has found negative association. In a line with this argument, Nerkar (2003) argued that the notion of balance also implies that high (low).

By contributing to further advancing the exploration-exploitation framework in cross-national firms, we also make a contribution to the international management literature. As the large portion of our sample consists of international firms (CIS 2006 micro data: Bulgaria, Cyprus, Czech Republic, Estonia, Norway, Portugal, Romania, United Kingdom, Slovakia, Slovenia, Spain and Switzerland) we contribute to the understanding the exploration-exploitation tensions along mix of different industries and national contexts. Although CIS data might be of doubtful quality in terms of accuracy of exploration and exploitation activities assessment, it leaves a room for further research. Although CIS data may have their shortcomings, they are well accepted by different scholars in exploration/exploitation research.

\section{Literature}

Atuahene-Gima, K. (2005). Resolving the capability-rigidity paradox in new product innovation. Journal of Marketing, 69(4), 61-83, http://dx.doi.org/10.1509/ jmkg.2005.69.4.61

Atuahene-Gima, K., \& Murray, J. Y. (2007). Exploratory and exploitative learning in new product development: a social capital perspective on new technology ventures in China. Journal of International Marketing, 15(02), 1-29, http://dx.doi.org/10.1509/jimk.15.2.1

Baum, J. A., Calabrese, T., \& Silverman, B. S. (2000). Don't go it alone: Alliance network composition and startups' performance in Canadian biotechnology. Strategic Management Journal, 21(3), 267-294, http:// dx.doi.org/10.1002/(SICI)1097-0266(200003)21:3<2 67::AID-SMJ89>3.0.CO;2-8

Benner, M. J., \& Tushman, M. (2002). Process management and technological innovation: A longitudinal study of the photography and paint industries. Administrative Science Quarterly, 47(4), 676-707, http://dx. doi.org/10.2307/3094913

Bierly, P. E., \& Daly, P. S. (2007). Alternative knowledge strategies, competitive environment, and organizational performance in small manufacturing firms. Entrepreneurship Theory and Practice, 31(4), 493-516, http://dx.doi.org/10.1111/j.1540-6520.2007.00185.x

Birkinshaw, J., \& Gupta, K. (2013). Clarifying the distinctive contribution of ambidexterity to the field of organization studies. The Academy of Management Perspectives, 27(4), 287-298, http://10.5465/amp.2012.0167

Blindenbach-Driessen, F., \& Ende, J. (2014). The Locus of Innovation: The Effect of a Separate Innovation Unit on Exploration, Exploitation, and Ambidexterity in Manufacturing and Service Firms. Journal of Product Innovation Management, 31(5), 1089-1105, http://dx. doi.org/10.1111/jpim. 12146

Cao, Q., Gedajlovic, E., \& Zhang, H. (2009). Unpacking organizational ambidexterity: Dimensions, contingencies, and synergistic effects. Organization Science, 20(4), 781-796, http://dx.doi.org/10.1287/ orsc. 1090.0426

Černe, M., Jaklič, M., \& Škerlavaj, M. (2013). Decoupling management and technological innovations: Resolving the individualism-collectivism controversy. Journal of International Management, 19(2), 103-117, http://10.1016/j.intman.2013.03.004

de Leeuw, T., Lokshin, B., \& Duysters, G. (2013). Returns to alliance portfolio diversity: The relative effects of partner diversity on firm's innovative performance and productivity, Journal of Business Research, 67(9), 1839-1849, http://dx.doi.org/10.1016/j.jbusres.2013.12.005

Gibson, C. B., \& Birkinshaw, J. (2004). The antecedents, consequences, and mediating role of organization- 
al ambidexterity. Academy of Management Journal, 47(2), 209-226, http://dx.doi.org/10.2307/20159573

Gupta, A. K., Smith, K. G., \& Shalley, C. E. (2006). The interplay between exploration and exploitation. Academy of Management Journal, 49(4), 693-706. http:// dx.doi.org/ 10.5465/AMJ.2006.22083026.

He, Z.-L., \& Wong, P.-K. (2004). Exploration vs. exploitation: An empirical test of the ambidexterity hypothesis. Organization Science, 15(4), 481-494, http://dx.doi. org/10.1287/orsc. 1040.0078

Hernández-Espallardo, M., Sánchez-Pérez, M., \& Segovia-López, C. (2011). Exploitation-and exploration-based innovations: the role of knowledge in inter-firm relationships with distributors. Technovation, 31(5), 203-215, http://dx.doi.org/10.1016/j.technovation.2011.01.007

Jansen, J. J., Simsek, Z., \& Cao, Q. (2012). Ambidexterity and performance in multiunit contexts: Cross-level moderating effects of structural and resource attributes. Strategic Management Journal, 33(11), http:// dx.doi.org/10.1002/smj.1977

Junni, P., Sarala, R. M., Taras, V., \& Tarba, S. Y. (2013). Organizational ambidexterity and performance: A meta-analysis. The Academy of Management Perspectives, 27(4), 299-312, http://dx.doi.org/10.5465/ amp.2012.0015

Kammerlander, N., Burger, D., Fust, A., \& Fueglistaller, U. (2014). Exploration and exploitation in established small and medium-sized enterprises: The effect of CEOs' regulatory focus. Journal of Business Venturing. In Press, http://dx.doi.org/10.1016/j. jbusvent.2014.09.004

Koza, M. P., \& Lewin, A. Y. (1998). The co-evolution of strategic alliances. Organization Science, 9(3), 255264, http://dx.doi.org/10.1287/orsc.9.3.255

Laursen, K., \& Salter, A. (2006). Open for innovation: the role of openness in explaining innovation performance among UK manufacturing firms. Strategic Management Journal, 27(2), 131-150, http://dx.doi. org/10.1002/smj.507

Lavie, D., \& Rosenkopf, L. (2006). Balancing exploration and exploitation in alliance formation. Academy of Management Journal, 49(4), 797-818, http://dx.doi. org/10.5465/AMJ.2006.22083085

Lavie, D., Stettner, U., \& Tushman, M. L. (2010). Exploration and exploitation within and across organizations. The Academy of Management Annals, 4(1), 109-155, http://dx.doi.org/10.1080/19416521003691287

Lubatkin, M. H., Simsek, Z., Ling, Y., \& Veiga, J. F. (2006). Ambidexterity and performance in smallto medium-sized firms: The pivotal role of top management team behavioral integration. Journal of Management, 32(5), 646-672, http://dx.doi. org/10.1177/0149206306290712

March, J. G. (1991). Exploration and exploitation in orga- nizational learning. Organization Science, 2(1), 71-87, http://www.jstor.org/stable/2634940

Nerkar, A. (2003). Old is gold? The value of temporal exploration in the creation of new knowledge. Management Science, 49(2), 211-229, http://dx.doi. org/10.1287/mnsc.49.2.211.12747

O'Reilly, C. A., \& Tushman, M. L. (2013). Organizational ambidexterity: Past, present, and future. The Academy of Management Perspectives, 27(4), 324-338, http:// dx.doi.org/10.5465/amp.2013.0025

O'Reilly, C. A., \& Tushman, M. L. (2004). The ambidextrous organization. Harvard Business Review, 82(4), 74-83.

O'Reilly, C. A., \& Tushman, M. L. (2008). Ambidexterity as a dynamic capability: resolving the innovator's dilemma. Research in Organizational Behavior, 28, 185206, http://dx.doi.org/10.1016/j.riob.2008.06.002

Oerlemans, L. A., Knoben, J., \& Pretorius, M. W. (2013). Alliance portfolio diversity, radical and incremental innovation: The moderating role of technology management. Technovation, 33(6), 234-246, http://dx.doi. org/10.1016/j.technovation.2013.02.004

Raisch, S., \& Birkinshaw, J. (2008). Organizational ambidexterity: Antecedents, outcomes, and moderators. Journal of Management, 34(3), 375-409, http://dx.doi. org/10.1177/0149206308316058

Raisch, S., Birkinshaw, J., Probst, G., \& Tushman, M. L. (2009). Organizational ambidexterity: Balancing exploitation and exploration for sustained performance. Organization Science, 20(4), 685-695, http://dx.doi. org/10.1287/orsc. 1090.0428

Rothaermel, F. T. (2001). Incumbent's advantage through exploiting complementary assets via interfirm cooperation. Strategic Management Journal, 22(6-7), 687699, http://dx.doi.org/10.1002/smj.180

Rothaermel, F. T., \& Alexandre, M. T. (2009). Ambidexterity in technology sourcing: The moderating role of absorptive capacity. Organization Science, 20(4), 759780, http://dx.doi.org/10.1287/orsc.1080.0404

Simsek, Z. (2009). Organizational ambidexterity: Towards a multilevel understanding. Journal of Management Studies, 46(4), 597-624, http://dx.doi.org/10.1111/ j.1467-6486.2009.00828.x

Stadler, C., Rajwani, T., \& Karaba, F. (2014). Solutions to the exploration/exploitation dilemma: Networks as a new level of analysis. International Journal of Management Reviews, 16(2), 172-193, http://dx.doi. org/10.1111/ijmr.12015

Stettner, U., \& Lavie, D. (2013). Ambidexterity under scrutiny: Exploration and exploitation via internal organization, alliances, and acquisitions. Strategic Management Journal, 35(13), 1903-1929, http://dx.doi. org/10.1002/smj.2195

Tushman, M. L., \& O'Reilly, C. A. (1996). Ambidextrous organizations: managing evolutionary and revolution- 
ary change. California management review, 38(4), 8-30.

Venkatraman, N., Lee, C.H., \& Iyer, B. (2007). Strategic ambidexterity and sales growth: tA longitudinal test in the software sector. (Working paper). Boston University.

Mladenka Popadić is an assistant at the Department of Management at the Faculty of Tourism and Hospitality Management in Opatija, University of Rijeka, Croatia. She is currently a Ph.D. student at the Faculty of Economics, University of Ljubljana, Slovenia. Her areas of research include strategic management, organization theory, inter-organizational relations, innovation, and alliances.

Matej Černe is an assistant professor at the Faculty of Economics, University of Ljubljana (the Department of Management and Organization), Head of the Open Innovation Systems Laboratory, co-Head of the Centre for
Innovation Research CERINNO Team Manager of the PACINNO project (Platform for trans-Academic Cooperation in INNOvation) at the Centre of Excellence for Biosensors, Instrumentation, and Process control (CO BIK), focused on investigating and promoting entrepreneurship and innovation in the Adriatic region. His areas of research include HRM, non-technological innovations, creativity, organizational behavior, leadership, and multi-level issues in management.

Ines Milohnić is Associate Professor at the Department of Management and Assistant Dean for Business Education and External Studies at the Faculty of Tourism and Hospitality Management in Opatija, University of Rijeka, Croatia. Her areas of research include entrepreneurial management and innovation, SMEs, competitive advantages and competitiveness in tourism and hospitality. She is the author of about seventy scientific papers and articles published in journals and proceedings in Croatia and abroad, and has participated in the development of scientific and technical studies and projects. 